\title{
Macro-Micro Combined Texture Evolution Model for Hot Strip with High Reduction Rolling
}

\author{
Toshiharu MORIMOTO, Fuyuki YOSHIDA, Yuji KUSUMOTO and Osamu AKISUE \\ Steel Research Department, Nakayama Steel Works Ltd., 1-1-66 Funamachi, Taisho-ku, Osaka 551-8551 Japan.
}

(Received on March 25, 2010; accepted on July 14, 2010)

\begin{abstract}
Techniques for controlling the texture of polycrystal materials are very important, because texture anisotropy has a strong effect not only on the characteristics of a steel sheet but also on the mechanical and electrical properties. We have produced fine-grained hot steel strips industrially through high-reduction lowtemperature rolling and these steels have the same texture as that of thermomechanically rolled steels. In this study, we first obtained the critical resolved shear stress of hot materials from functions of dislocation density and predicted the hot rolling texture in the nonrecrystallized austenite region using Taylor theory. Next, we predicted the transformation texture of fine-grained hot strips from the hot rolling texture of austenite in accordance with the Kurdjumov-Sachs orientation relationship. The accuracy of the new macro-micro combined model for texture evolution is excellent.
\end{abstract}

KEY WORDS: texture; texture control; fine grain strip; mathematical model; crystal plasticity.

\section{Introduction}

Because texture strongly affects the mechanical and electromagnetic properties of polycrystal products, it is important to produce materials with optimized texture. Techniques for controlling the texture of materials are very important for obtaining useful products with texture anisotropy, because there is a correlation between the material characteristics and texture. ${ }^{1,2)}$

A rolling texture is obtained during the thermomechanical rolling of a hot strip in the nonrecrystallized austenite region, and it has a significant impact not only on the inherited ferrite transformation texture but also on the recrystallization texture of a cold strip. ${ }^{3,4)}$ Thus, it is necessary to study the formation mechanism of the rolling texture in hot rolling to improve the properties of hot and cold strips. Moreover, for stainless steel, which does not transform after hot rolling, the rolling texture has a particularly strong effect on the final characteristics of the strip, and the technique of texture control is being improved continuously. ${ }^{5-7)}$

We have industrially produced fine-grained hot strips. A brief explanation of the metallurgical principles involved in their production is as follows. At a rougher stand and at previous stands of the finishing train, recrystallized finegrained austenite is manufactured by high-temperature, high-reduction rolling. At later stands of the finishing train, a nonrecrystallized strained flat austenite is manufactured by low-temperature, high-reduction rolling. Heavy residual strains can result in a fine-grained ferrite strip after coiling. Thus, this steel may have a significant rolling texture at later stands of the finishing train, the same as that of a thermomechanically rolled steel. Taylor ${ }^{8)}$ analyzed deformation texture at the beginning of the 20th century, and in many subsequent investigations, the finite element method has often been used to predict rolling texture..$^{9-13)}$

We predicted the hot rolling texture using conventional Taylor theory coupled with the Asaro rate-dependent rule. ${ }^{9)}$ However, our study features three original points. Hereafter, macro stresses, macro strains and total spins acted on the polycrystal and were calculated by deformation analysis. In contrast, micro stresses, micro strains and plastic spins acted on a single crystal and were used to predict rolling texture. First, macro stresses, macro strains and total spins were calculated using Orowan theory, based on which stress equilibrium equations were solved. Orowan theory enables us to predict macro stresses, macro strains and total spins in a reasonably short computing time. Secondly, we calculated the hot flow stress of hot materials as functions of dislocation density ${ }^{14)}$ and obtained the critical resolved shear stress of hot materials. In the conventional texture evolution method. ${ }^{9}{ }^{12)}$ self hardening and latent hardening moduli are introduced to predict critical resolved shear stress only for cold rolling using many material parameters. However, it is difficult to determine the many material parameters in the case of hot rolling, as demonstrated by laboratory experience. The ferrite transformation texture is inherited from the austenite rolling texture in accordance with the Kurdjumov-Sachs orientation relationship. ${ }^{15,16)}$ A variant selection rule has been previously formulated so that the transformation strain from austenite to ferrite is minimized. ${ }^{17-19)}$ However, little research has since been carried out on the prediction of rolling texture and transformation texture. Thus thirdly, we predicted the transformation texture using the predicted rolling texture of a hot strip rolled with high reduction at a low temperature. 


\section{Mathematical Model}

Figure 1 shows the metallurgical phenomena in a tandem hot strip mill. Figure 2 shows the macro-micro combined model for microstructure and texture evolution and the analytical elements that constitute this model. In hot strip rolling, plastic deformation, a change in the microstructure owing to recrystallization and transformation, and a temperature transition occur at the same time. To precisely analyze such a complex field where deformation, microstructure changes and a temperature transition interact with each other, we must calculate them more than twice. Therefore, we used Orowan theory for deformation analysis instead of the finite element method. ${ }^{14)}$ Macro stresses, macro strains, total spins and flow stress, which are calculated by the conventional macro-micro combined model, are transferred to the new macro-micro combined model for texture. In Taylor theory, as shown in Eq. (1), the micro strain tensor $\boldsymbol{\varepsilon}$ is assumed to be equal to the macro strain tensor $\mathbf{E}$, while the macro stress tensor $\mathbf{S}$ is assumed not to be equal to the micro stress tensor $\sigma$.

$$
\boldsymbol{\varepsilon}=\mathbf{E}, \quad \boldsymbol{\sigma} \neq \mathbf{S}
$$

In Taylor theory, the strain continuity of crystals is realized, but not all real crystals have the same strain. We adopted Taylor theory to predict the rolling texture. Also in the new model, calculated Euler angles for the rolling texture are used to predict the transformation texture.

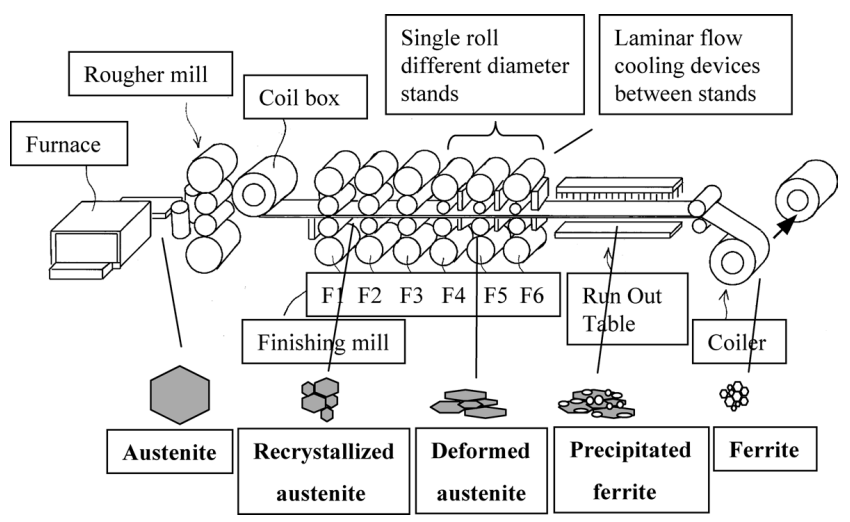

Fig. 1. Schematic illustration of microstructure evolution in the tandem hot strip mill.

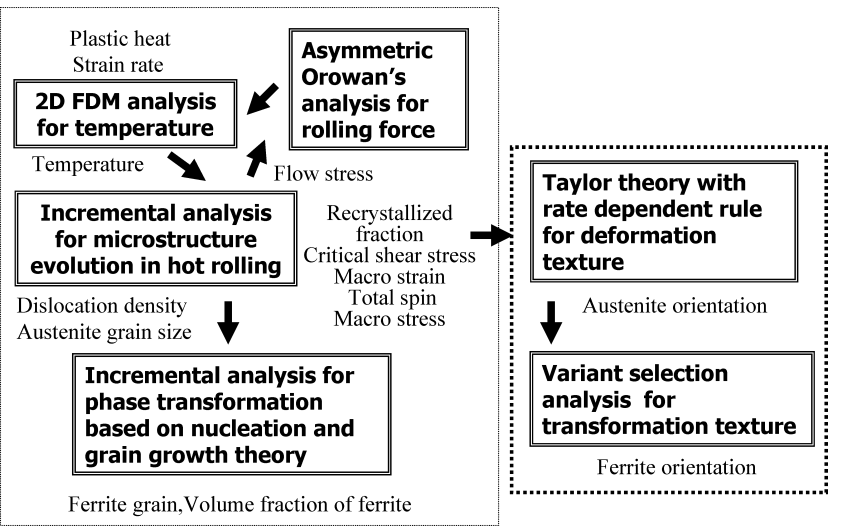

Fig. 2. Macro-micro combined model for microstructure and texture evolution in the tandem hot strip mill.

\section{Rolling Texture Analysis}

\subsection{Three Types of Spin}

In rolling texture analysis, we used three types of spin. Here, we explain the differences among the three types of spin using the equations and figures below. On the basis of Lee's elastic-plastic decomposition of a deforming material, ${ }^{20)}$ the deformation gradient tensor $\mathbf{F}$ and velocity gradient tensor $\mathbf{L}$ of a crystal can be expressed using the following equations.

$$
\begin{gathered}
\mathbf{F}=\mathbf{R} \cdot \mathbf{U} \\
\mathbf{L}=\mathbf{D}+\mathbf{W}
\end{gathered}
$$

Here, $\mathbf{R}, \mathbf{U}, \mathbf{D}$ and $\mathbf{W}$ are the rotation tensor, stretch tensor, strain rate tensor, and total spin tensor, respectively. The symmetric part of Eq. (3) is expressed as

$$
\mathbf{D}=\frac{1}{2} \mathbf{R} \cdot\left(\dot{\mathbf{U}} \cdot \mathbf{U}^{-1}+\mathbf{U}^{-1} \cdot \dot{\mathbf{U}}\right) \cdot \mathbf{R}^{\mathbf{T}} \boldsymbol{\emptyset} \mathbf{D}^{\mathbf{P}}
$$

The asymmetric part of Eq. (3) is expressed as

$$
\mathbf{W}=\dot{\mathbf{R}} \cdot \mathbf{R}^{\mathbf{T}}+\frac{1}{2} \mathbf{R} \cdot\left(\dot{\mathbf{U}} \cdot \mathbf{U}^{-1}-\mathbf{U}^{-1} \cdot \dot{\mathbf{U}}\right) \cdot \mathbf{R}^{\mathbf{T}}=\mathbf{W}+\mathbf{W}^{\mathbf{P}}
$$

Here, $\mathbf{D}^{\mathbf{P}}, \boldsymbol{\Omega}$, and $\mathbf{W}^{\mathbf{P}}$ are the plastic strain rate tensor, lattice rotation tensor and plastic spin tensor, respectively. Figure 3 shows the total spin, plastic spin and lattice rotation spin on a rolled crystal. Rolling basically involves compression with shearing on the surface of the rolled product; the shearing direction changes via a neutral point. At the center in the thickness direction, the crystal is deformed and becomes quadrilateral. As the deformation occurs by crystal slippage, the crystals are rotated counterclockwise in accordance with the Taylor compression rule. This spin is called the plastic spin tensor $\mathbf{W}^{\mathbf{P}}$. In contrast, at the surface, the crystal is both compressed and sheared and becomes a parallelogram. Applying a shearing deformation, the crystals are rotated clockwise in the backward slip region and counterclockwise in the forward slip region. This spin is called the total spin tensor $\mathbf{W}$. As a result, the lattice rotation spin tensor $\boldsymbol{\Omega}$ at the surface is larger than that at the center in the thickness direction, as indicated by Eqs. (6) and (7).

$$
\begin{array}{ll}
\Omega=-\mathbf{W}^{\mathbf{P}} & \text { at center } \\
\Omega=\mathbf{W}-\mathbf{W}^{\mathbf{P}} & \text { at surface }
\end{array}
$$

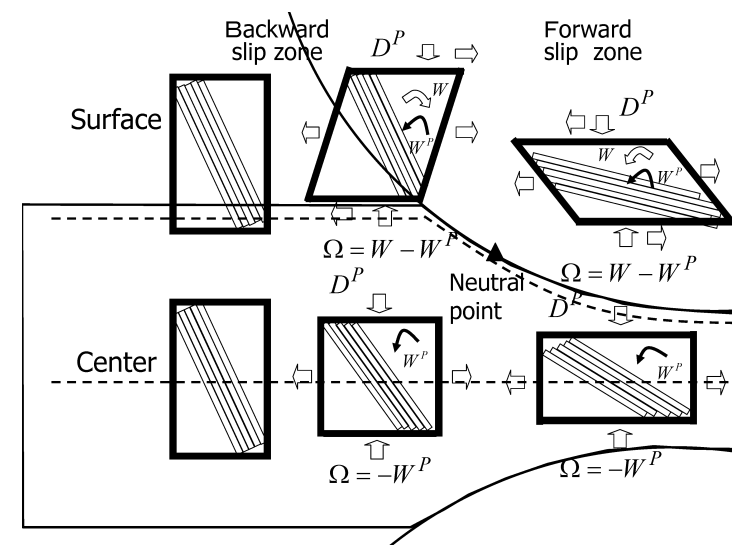

Fig. 3. Schematic illustration of lattice rotation by hot rolling. 


\subsection{Total Spins Calculated Using Orowan Theory}

In this model, the total spins are calculated implicitly using Orowan theory, while in the finite element method, they are obtained as a result of explicit calculation. ${ }^{9-13)}$ The quadrilateral $\mathrm{ABCD}$, for which the stress equilibrium equations are solved, is assumed to become the quadrilateral $\mathrm{A}^{\prime} \mathrm{B}^{\prime} \mathrm{C}^{\prime} \mathrm{D}^{\prime}$ after rolling, as shown in Fig. 4. Here, $\mathrm{B}^{\prime}$ is the point at which the contact length is divided equally, and $\mathrm{D}^{\prime}$ is the point at which the Orowan arc is divided equally. Figure 5 shows the flow chart that we use to calculate the total spins on the basis of Orowan theory. The displacement vector $\mathbf{u}$ can be expressed using the following equations. ${ }^{21)}$

$$
\begin{aligned}
& u_{x}^{B}=u_{x}^{A}+\Delta u_{x}^{A B} \\
& u_{y}^{B}=u_{y}^{A}+\Delta u_{y}^{A B} \\
& u_{x}^{D}=u_{x}^{A}+\Delta u_{x}^{A D} \\
& u_{y}^{D}=u_{y}^{A}+\Delta u_{y}^{A D}
\end{aligned}
$$

We apply the Taylor expansion theorem around point A. Then,

$$
\Delta u_{x}^{A B}=\left(\frac{\partial u_{x}(x, y)}{\partial x}\right) \Delta x^{A B}+\left(\frac{\partial u_{x}(x, y)}{\partial y}\right) \Delta y^{A B}
$$

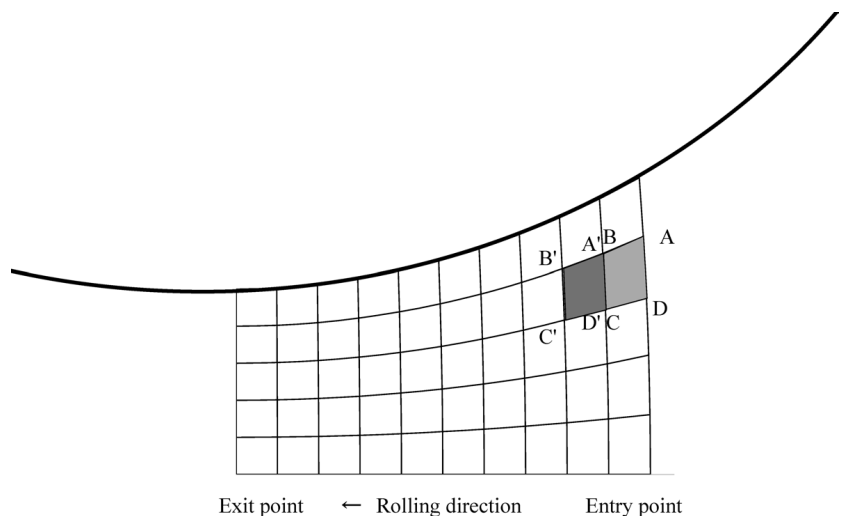

Fig. 4. Deformation slab calculated using the Orowan rolling theory.

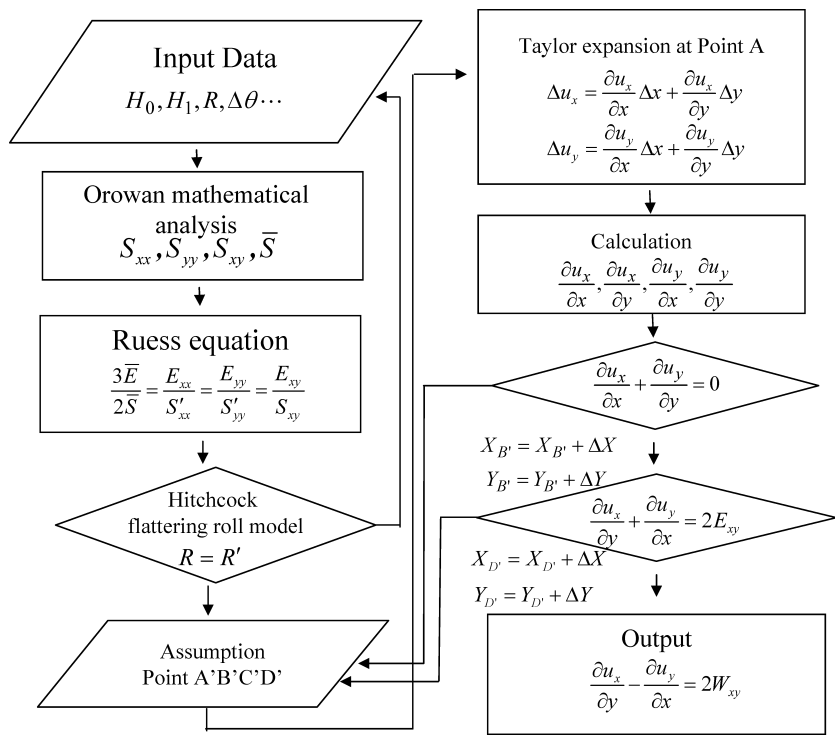

Fig. 5. Flow chart of calculation for total spin by the Orowan rolling theory.

$$
\begin{gathered}
\Delta u_{y}^{A B}=\left(\frac{\partial u_{y}(x, y)}{\partial x}\right) \Delta x^{A B}+\left(\frac{\partial u_{y}(x, y)}{\partial y}\right) \Delta y^{A B} \ldots \\
\Delta u_{x}^{A D}=\left(\frac{\partial u_{x}(x, y)}{\partial x}\right) \Delta x^{A D}+\left(\frac{\partial u_{x}(x, y)}{\partial y}\right) \Delta y^{A D} \ldots \\
\Delta u_{y}^{A D}=\left(\frac{\partial u_{y}(x, y)}{\partial x}\right) \Delta x^{A D}+\left(\frac{\partial u_{y}(x, y)}{\partial y}\right) \Delta y^{A D} \ldots \\
\frac{\partial u_{x}(x, y)}{\partial x}=\frac{\Delta y^{A B} \Delta u_{x}^{A D}-\Delta y^{A D} \Delta u_{x}^{A B}}{\Delta x^{A D} \Delta y^{A B}-\Delta y^{A D} \Delta x^{A B}} \ldots \ldots \ldots \\
\frac{\partial u_{x}(x, y)}{\partial x}=\frac{\Delta y^{A B} \Delta u_{x}^{A D}-\Delta x^{A D} \Delta u_{x}^{A B}}{\Delta x^{A B} \Delta y^{A D}-\Delta y^{A B} \Delta x^{A D}} \ldots \ldots \ldots . . \\
\frac{\partial u_{y}(x, y)}{\partial x}=\frac{\Delta y^{A B} \Delta u_{y}^{A D}-\Delta y^{A D} \Delta u_{y}^{A B}}{\Delta x^{A D} \Delta y^{A B}-\Delta y^{A D} \Delta x^{A B}} \ldots \ldots \ldots . . \\
\frac{\partial u_{y}(x, y)}{\partial x}=\frac{\Delta x^{A B} \Delta u_{y}^{A D}-\Delta x^{A D} \Delta u_{y}^{A B}}{\Delta x^{A B} \Delta y^{A D}-\Delta y^{A B} \Delta x^{A D}} \ldots \ldots \ldots . .
\end{gathered}
$$

Next, by moving point $\mathrm{B}^{\prime}$ along the contact length and point $\mathrm{D}^{\prime}$ along the Orowan arc, we determine point $\mathrm{B}^{\prime}$ at which Eq. (20) is satisfied and point $\mathrm{D}^{\prime}$ at which Eq. (21) is satisfied.

$$
\begin{gathered}
\frac{\partial u_{x}(x, y)}{\partial x}+\frac{\partial u_{y}(x, y)}{\partial y}=E_{x x}+E_{y y}=0 \\
\frac{\partial u_{x}(x, y)}{\partial y}+\frac{\partial u_{y}(x, y)}{\partial x}=2 E_{x y} \ldots \ldots . . .
\end{gathered}
$$

Here, E represents the macro strain tensor for which the stress equilibrium equations are solved by Orowan theory. Finally, we calculate the total spins as follows.

$$
\frac{\partial u_{x}(x, y)}{\partial y}-\frac{\partial u_{y}(x, y)}{\partial x}=2 W_{x y}
$$

\subsection{Relationship of Displacements to Slips in the Slip Plane of Lattice}

A displacement velocity vector $\dot{\mathbf{u}}$ can be expressed as follows. ${ }^{10}$

$$
\dot{\mathbf{u}}=\dot{\gamma}(\mathbf{x} \cdot \mathbf{a}) \mathbf{b}
$$

Here, $\dot{\gamma}, \mathbf{x}$, a and $\mathbf{b}$ are the slip rate, position, a unit vector normal to the slipping plane and a unit vector in the slipping direction, respectively. Thus, the plastic strain rate tensor $\mathbf{D}^{\mathbf{P}}$ and plastic spin tensor $\mathbf{W}^{\mathbf{P}}$ can be defined using Eqs. (24) and (25), respectively. ${ }^{9)}$

$$
\begin{aligned}
& D_{i j}^{p}=\frac{1}{2}\left(\frac{\partial \dot{u}_{j}}{\partial x_{i}}+\frac{\partial \dot{u}_{i}}{\partial x_{j}}\right)=\frac{1}{2} \dot{\gamma}\left(a_{i} b_{j}+a_{j} b_{i}\right)=P_{i j} \dot{\gamma} \\
& W_{i j}^{p}=\frac{1}{2}\left(\frac{\partial \dot{u}_{j}}{\partial x_{i}}-\frac{\partial \dot{u}_{i}}{\partial x_{j}}\right)=\frac{1}{2} \dot{\gamma}\left(a_{i} b_{j}-a_{j} b_{i}\right)=Q_{i j} \dot{\gamma}
\end{aligned}
$$

Here,

$$
P_{i j}=\frac{1}{2}\left(a_{i} b_{j}+a_{j} b_{i}\right)
$$




$$
Q_{i j}=\frac{1}{2}\left(a_{i} b_{j}-a_{j} b_{i}\right)
$$

An f.c.c. crystal lattice has twelve $\{111\}\langle 110\rangle$ slip systems.

\subsection{Determination of Slip Rate and Rotation Tensor}

To determine the slip rate and rotation tensor in hot rolling, we need the critical resolved shear stress of hot materials. Thus, we calculated flow stress of hot materials as functions of dislocation density ${ }^{14)}$ and obtained a critical resolved shear stress satisfying the equations below. The strain equilibrium, the shear stress of each slip system and the rate-dependent rule are expressed using Eqs. (28), (29) and (30), respectively. Equation (28) means that the sum of the incremental slip values $d \gamma$ of each slip system in one crystal is equal to the sum of incremental micro strain tensor $\mathbf{d} \boldsymbol{\varepsilon}$. Equation (29) gives the relationship between the micro stress tensor $\sigma$ acting on the single crystal and the resolved shear stress $\tau$ in the slipping direction on the slip plane of each crystal. Equation (30) is the Asaro rate-dependent rule and $m$ is a material parameter. ${ }^{9)}$

$$
\begin{aligned}
& d \varepsilon_{i}=\sum P_{i j} d \gamma_{j} \\
& \tau_{j}=\sum P_{i j} \sigma_{i} \\
& d \gamma_{j}=\dot{\gamma}_{0} \cdot d t \cdot\left(\frac{\tau_{j}}{\tau_{y}}\right)^{1 / m} \cdot \operatorname{sign}\left(\tau_{j}\right)
\end{aligned}
$$

Here, $\dot{\gamma}_{0}, \tau_{y}$ and $d t$ are the reference value of slip strain rate, the critical resolved shear stress and the time increment, respectively. The critical resolved shear stress $\tau_{y}$ in the slipping direction on the slip plane is determined from the flow stress, as shown in Eq. (31), which is calculated using the macro-micro combined model for microstructure evolution. ${ }^{14)}$ In Eq. (31), $\bar{S}, \bar{E}$ and $\dot{\bar{E}}$ are the equivalent macro stress, equivalent macro strain and equivalent macro strain rates, respectively. $\rho$ is the analyzed dislocation density of the rolled material and is a variable parameter in the incremental formulation. ${ }^{22,23)}$ The Taylor factor of f.c.c. crystals is 3.07 .

$$
\tau_{y}=\bar{S}(\bar{E}, \dot{\bar{E}}, \rho) / \text { Taylor factor }
$$

The rotation tensor $\mathbf{R}$ is obtained using

$$
\begin{array}{r}
\dot{\mathbf{R}}=\mathbf{\Omega} \cdot \mathbf{R} \ldots \ldots \ldots \ldots \ldots \ldots \\
\mathbf{R}=\exp \mathbf{\Omega} d t \fallingdotseq \mathbf{I}+d t \mathbf{\Omega}+1 / 2 d t^{2} \mathbf{\Omega}
\end{array}
$$

I is identity tensor.

\subsection{Hot Rolling Texture Analysis}

Figures 6 and 7 show the predicted and observed conventional hot rolling texture of austenite stainless steel, SUS304, which does not transform after rolling. Table 1 shows the chemical composition and pass schedule used for the actual rolling of SUS304. Considering the material parameters of SUS304, $m$ is $0.05, \dot{\gamma}_{0}$ is 100 and flow stress is measured during actual tandem hot rolling. Some parts of the texture appear to be the same, whereas others do not.In the (111) pole figure in Fig. 6, there is a slight difference between the predicted and observed textures. We consider that the lower prediction accuracy of the SUS304 hot rolling texture is a result of assuming that the 12 critical

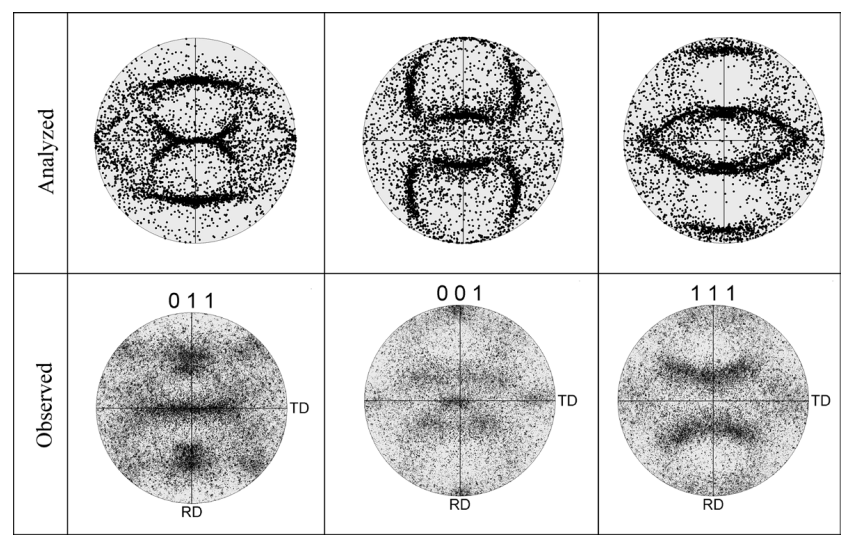

Fig. 6. Analyzed and observed hot rolling texture of austenite stainless steel rolled with conventional schedule at center of thickness.

\begin{tabular}{|c|c|c|c|c|c|c|}
\hline $\mathrm{C}$ & $\mathrm{Si}$ & $\mathrm{Mn}$ & $\mathrm{P}$ & S & $\mathrm{Cr}$ & $\mathrm{Ni}$ \\
\hline $0.07 \%$ & $0.59 \%$ & $1.45 \%$ & $0.025 \%$ & $0.009 \%$ & $18.43 \%$ & $8.31 \%$ \\
\hline $\begin{array}{l}\text { Entry } \\
\text { thick. }\end{array}$ & F1 & $\mathrm{F} 2$ & $\mathrm{~F} 3$ & $\mathrm{~F} 4$ & F5 & $\begin{array}{l}\text { Exit } \\
\text { thick. }\end{array}$ \\
\hline $32 \mathrm{~mm}$ & $18 \mathrm{~mm}$ & $10.5 \mathrm{~mm}$ & $5.9 \mathrm{~mm}$ & $4.2 \mathrm{~mm}$ & $3.5 \mathrm{~mm}$ & $3 \mathrm{~mm}$ \\
\hline \multicolumn{2}{|c|}{$\begin{array}{l}\text { Entry temp. } \\
\text { of finshier }\end{array}$} & \multicolumn{2}{|c|}{$\begin{array}{l}\text { Exit temp. } \\
\text { of finisher }\end{array}$} & \multicolumn{2}{|c|}{ Coiling temp. } & \\
\hline & $1026^{\circ} \mathrm{C}$ & & $991^{\circ} \mathrm{C}$ & & $862^{\circ} \mathrm{C}$ & \\
\hline
\end{tabular}

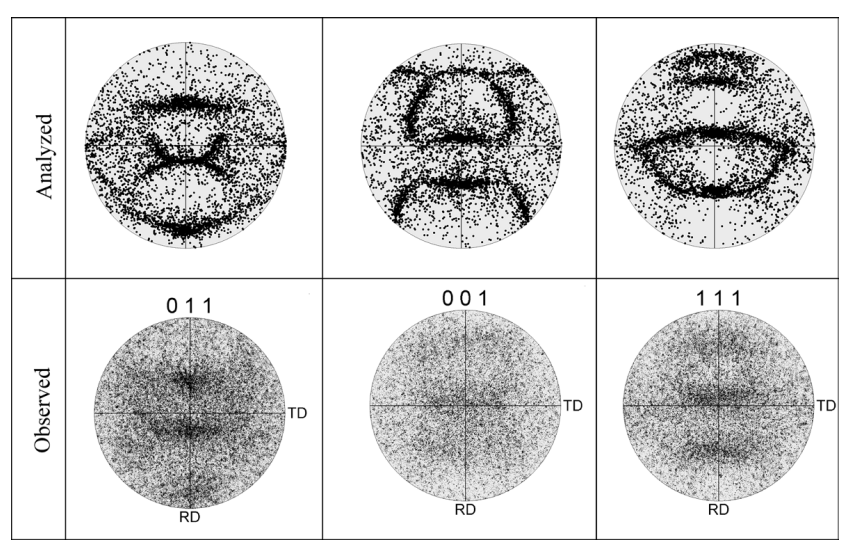

Fig. 7. Analyzed and observed hot rolling texture of austenite stainless steel rolled with conventional schedule at surface.

Table 1. Chemical composition and conventional finisher rolling schedule of austenite stainless steel.

shear stresses of the 12 slip systems of SUS304 are equal. Moreover, the hot rolling textures of SUS304 are weak because of the partial recrystallization during the finishing rolls. Figure 7 shows that the hot rolling texture of the surface is inclined toward the rolling direction by the total spin, as shown in Eq. (7).

\section{Transformation Texture Analysis}

We predicted the transformation texture in accordance with the variant selection rules ${ }^{17,18)}$ using the predicted hot rolling texture of a steel strip rolled with high reduction at a low temperature. Figure 8 shows the flow chart that we used to determine the transformation texture, and Table 2 shows the coordinate transformation matrix of the Kurdjumov-Sachs orientation relationship between the 24 vari- 


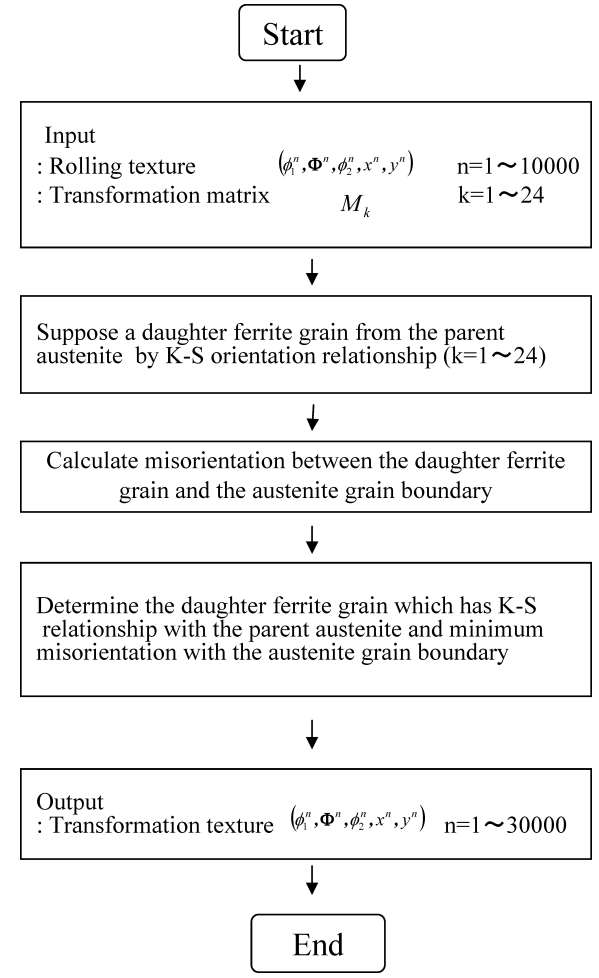

Fig. 8. Flow chart of calculation for transformation texture by the Kurdjumov-Sachs orientation relationship. ants. ${ }^{24,25)}$ Table 3 shows the chemical composition of the steel and the pass schedule used for the actual rolling. This steel has a plain carbon composition without any rare earth metals. The pass schedule yields high reduction at a low temperature at the later stands in the finishing train. The exit temperature in the finishing train is slightly above $\mathrm{Ar}_{3}$, which is the ferrite transformation temperature of this steel. Before predicting the transformation texture, we analyzed the strip recrystallization rate of each pass in the finishing train using the macro-micro combined model. ${ }^{14)}$ Figure 9 shows the analyzed dynamic recrystallized fraction and the static recrystallized fraction of each pass. The total recrystallized fraction stand F6 was found to be about 0.3 . Hence, assuming that the last pass in the finishing train is almost in the nonrecrystallized region, we calculated only the last pass schedule to predict the hot rolling texture before transformation. Figures $\mathbf{1 0}$ and $\mathbf{1 1}$ show the predicted and observed transformation textures of fine-grained plain carbon steel, respectively. Figure 10 shows that the prediction accuracy of the transformation texture is good at the center in the thickness direction. However, as shown in Fig. 11, there is considerable difference between the predicted and observed transformation textures on the surface of the strip. We consider that before transformation, dynamic or static recrystallization may have occurred. Because the shear deformation on the surface of the strip is proportional to the rolling reduction, the shear strain of the last stand of high reduction rolling is large. ${ }^{26,27)}$ The addition of shear defor-

Table 2. Coordinate transformation matrix of Kurdjmov-Sachs orientation relationship between 24 variants.

\begin{tabular}{|c|c|c|c|c|c|c|c|c|c|c|c|c|c|}
\hline \multirow[t]{2}{*}{$\begin{array}{l}\text { Variant } \\
\text { No. }\end{array}$} & \multirow[t]{2}{*}{$\begin{array}{l}\text { Plane } \\
\text { parallel }\end{array}$} & \multicolumn{2}{|c|}{$\begin{array}{c}\text { Direction } \\
\text { parallel }\end{array}$} & \multirow{2}{*}{\multicolumn{3}{|c|}{$\begin{array}{c}\text { Coordinate transformation } \\
\text { matrix } \mathbf{M}\end{array}$}} & \multirow[t]{2}{*}{$\begin{array}{l}\text { Variant } \\
\text { No. }\end{array}$} & \multirow[t]{2}{*}{$\begin{array}{l}\text { Plane } \\
\text { parallel }\end{array}$} & \multicolumn{2}{|c|}{$\begin{array}{l}\text { Direction } \\
\text { parallel }\end{array}$} & \multirow{2}{*}{\multicolumn{3}{|c|}{$\begin{array}{c}\text { Coordinate transformation } \\
\text { matrix } \mathbf{M}\end{array}$}} \\
\hline & & {$[\gamma]$} & {$[\alpha]$} & & & & & & {$[\gamma]$} & {$[\alpha]$} & & & \\
\hline \multirow{3}{*}{ V1 } & \multirow{18}{*}{$\begin{array}{l}(111) \gamma \\
/ /(011) \alpha\end{array}$} & \multirow{3}{*}{$-1,0,1$} & \multirow{3}{*}{$-1,-1,1$} & 0.7416 & -0.6667 & -0.0749 & \multirow{3}{*}{ V13 } & \multirow{18}{*}{$\begin{array}{l}(-111) \gamma \\
/ /(011) \alpha\end{array}$} & \multirow{3}{*}{$0,-1,1$} & \multirow{3}{*}{$-1,-1,1$} & 0.6667 & 0.7416 & -0.0749 \\
\hline & & & & 0.6498 & 0.7416 & -0.1667 & & & & & -0.7416 & 0.6498 & $\begin{array}{r}-0.1667 \\
\end{array}$ \\
\hline & & & & 0.1667 & 0.0749 & 0.9832 & & & & & -0.0749 & 0.1667 & 0.9832 \\
\hline \multirow{3}{*}{$\mathrm{V} 2$} & & \multirow{3}{*}{$-1,0,1$} & \multirow{3}{*}{$-1,1,-1$} & 0.0749 & 0.6667 & -0.7416 & \multirow{3}{*}{ V14 } & & \multirow{3}{*}{$0,-1,1$} & \multirow{3}{*}{$-1,1,-1$} & -0.6667 & 0.0749 & -0.7416 \\
\hline & & & & -0.1667 & 0.7416 & 0.6498 & & & & & -0.7416 & -0.1667 & 0.6498 \\
\hline & & & & 0.9832 & 0.0749 & 0.1667 & & & & & -0.0749 & 0.9832 & 0.1667 \\
\hline \multirow{3}{*}{ V3 } & & & & -0.6667 & -0.0749 & 0.7416 & & & & & 0.0749 & $\begin{array}{r}-0.6667 \\
\end{array}$ & 0.7416 \\
\hline & & $0,1,-1$ & $-1,-1,1$ & 0.7416 & -0.1667 & 0.6498 & V15 & & $-1,0,-1$ & $-1,-1,1$ & 0.1667 & 0.7416 & 0.6498 \\
\hline & & & & 0.0749 & 0.9832 & 0.1667 & & & & & -0.9832 & 0.0749 & 0.1667 \\
\hline & & & & 0.6667 & -0.7416 & 0.0749 & & & & & 0.7416 & 0.6667 & 0.0749 \\
\hline V4 & & $0,1,-1$ & $-1,1,-1$ & 0.7416 & 0.6498 & -0.1667 & V16 & & $-1,0,-1$ & $-1,1,-1$ & -0.6498 & 0.7416 & -0.1667 \\
\hline & & & & 0.0749 & 0.1667 & 0.9832 & & & & & -0.1667 & 0.0749 & 0.9832 \\
\hline & & & & -0.0749 & 0.7416 & -0.6667 & & & & & -0.7416 & $\begin{array}{r}-0.0749 \\
\end{array}$ & $\begin{array}{r}-0.6667 \\
\end{array}$ \\
\hline V5 & & $1,-1,0$ & $-1,-1,1$ & -0.1667 & 0.6498 & 0.7416 & V17 & & $1,1,0$ & $-1,-1,1$ & -0.6498 & -0.1667 & 0.7416 \\
\hline & & & & 0.9832 & 0.1667 & 0.0749 & & & & & -0.1667 & 0.9832 & 0.0749 \\
\hline & & & & -0.7416 & 0.0749 & 0.6667 & & & & & -0.0749 & -0.7416 & 0.6667 \\
\hline V6 & & $1,-1,0$ & $-1,1,-1$ & 0.6498 & -0.1667 & 0.7416 & V18 & & $1,1,0$ & $-1,1,-1$ & 0.1667 & 0.6498 & 0.7416 \\
\hline & & & & 0.1667 & 0.9832 & 0.0749 & & & & & -0.9832 & 0.1667 & 0.0749 \\
\hline & & & & -0.0749 & 0.6667 & 0.7416 & & & & & 0.7416 & -0.0749 & 0.6667 \\
\hline V7 & & $1,0,-1$ & $-1,-1,1$ & -0.1667 & -0.7416 & 0.6498 & V19 & & $-1,1,0$ & $-1,-1,1$ & 0.6498 & -0.1667 & -0.7416 \\
\hline & & & & 0.9832 & -0.0749 & 0.1667 & & & & & 0.1667 & 0.9832 & -0.0749 \\
\hline & & & & -0.7416 & -0.6667 & 0.0749 & & & & & 0.0749 & -0.7416 & -0.6667 \\
\hline V8 & & $1,0,-1$ & $-1,1,-1$ & 0.6498 & -0.7416 & -0.1667 & V20 & & $-1,1,0$ & $-1,1,-1$ & -0.1667 & 0.6498 & -0.7416 \\
\hline & & & & 0.1667 & -0.0749 & 0.9832 & & & & & 0.9832 & 0.1667 & -0.0749 \\
\hline & & & & 0.7416 & 0.0749 & -0.6667 & & & & & -0.6667 & 0.7416 & 0.0749 \\
\hline V9 & & $-1,-1,0$ & $-1,-1,1$ & 0.6498 & 0.1667 & 0.7416 & V21 & & $0,-1,-1$ & $-1,-1,1$ & 0.7416 & 0.6498 & 0.1667 \\
\hline & $(1-11) \gamma$ & & & 0.1667 & -0.9832 & 0.0749 & & $(11-1) \gamma$ & & & 0.0749 & 0.1667 & -0.9832 \\
\hline & $/ /(011) \alpha$ & & & 0.0749 & 0.7416 & 0.6667 & & $/ /(011) \alpha$ & & & 0.6667 & 0.0749 & 0.7416 \\
\hline V10 & & $-1,-1,0$ & $-1,1,-1$ & -0.1667 & -0.6498 & 0.7416 & V22 & & $0,-1,-1$ & $-1,1,-1$ & 0.7416 & -0.1667 & -0.6498 \\
\hline & & & & 0.9832 & -0.1667 & 0.0749 & & & & & 0.0749 & 0.9832 & -0.1667 \\
\hline & & & & -0.6667 & -0.7416 & -0.0749 & & & & & -0.0749 & -0.6667 & -0.7416 \\
\hline V11 & & $0,1,1$ & $-1,-1,1$ & 0.7416 & -0.6498 & -0.1667 & V23 & & $1,0,1$ & $-1,-1,1$ & -0.1667 & 0.7416 & -0.6498 \\
\hline & & & & 0.0749 & -0.1667 & 0.9832 & & & & & 0.9832 & 0.0749 & -0.1667 \\
\hline & & & & 0.6667 & -0.0749 & -0.7416 & & & & & -0.7416 & 0.6667 & -0.0749 \\
\hline V12 & & $0,1,1$ & $-1,1,-1$ & 0.7416 & 0.1667 & 0.6498 & V24 & & $1,0,1$ & $-1,1,-1$ & 0.6498 & 0.7416 & 0.1667 \\
\hline & & & & 0.0749 & -0.9832 & 0.1667 & & & & & 0.1667 & 0.0749 & -0.9832 \\
\hline
\end{tabular}


Table 3. Chemical composition and new finisher rolling schedule of plain carbon fine grain steel.

\begin{tabular}{|c|c|c|c|c|c|c|}
\hline $\mathrm{C}$ & $\mathrm{Si}$ & $\mathrm{Mn}$ & $\mathrm{P}$ & $\mathrm{S}$ & T.Al & REM \\
\hline $0.15 \%$ & $0.35 \%$ & $1.42 \%$ & $0.010 \%$ & $0.005 \%$ & $0.035 \%$ & $0 \%$ \\
\hline $\begin{array}{l}\text { Entry } \\
\text { thick. }\end{array}$ & F1 & $\mathrm{F} 2$ & F3 & $\mathrm{F} 4$ & F5 & $\begin{array}{l}\text { Exit } \\
\text { thick. }\end{array}$ \\
\hline $39.8 \mathrm{~mm}$ & $24.6 \mathrm{~mm}$ & $15.5 \mathrm{~mm}$ & $10.5 \mathrm{~mm}$ & $6.3 \mathrm{~mm}$ & $3.7 \mathrm{~mm}$ & $2.1 \mathrm{~mm}$ \\
\hline \multicolumn{2}{|c|}{\begin{tabular}{c|} 
Entry temp. \\
of finshier
\end{tabular}} & \multicolumn{2}{|c|}{$\begin{array}{c}\text { Exit temp. }{ }^{(*)} \\
\text { of finisher }\end{array}$} & \multicolumn{2}{|c|}{ Coiling temp. } & \\
\hline & $987^{\circ} \mathrm{C}$ & & $781^{\circ} \mathrm{C}$ & & $615^{\circ} \mathrm{C}$ & \\
\hline
\end{tabular}

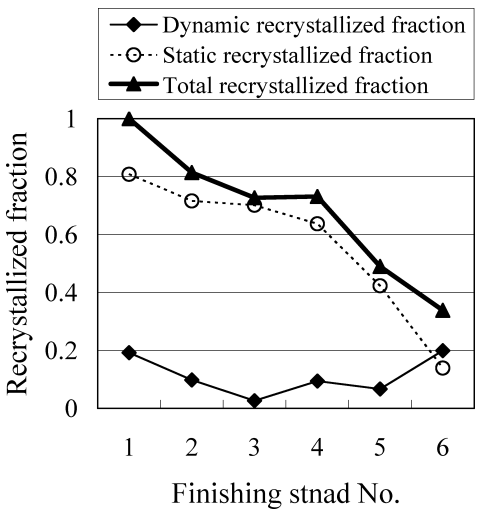

Fig. 9. Analyzed recrystallized fraction of each stand in the finishing train rolled with high reduction and low temperature schedule.

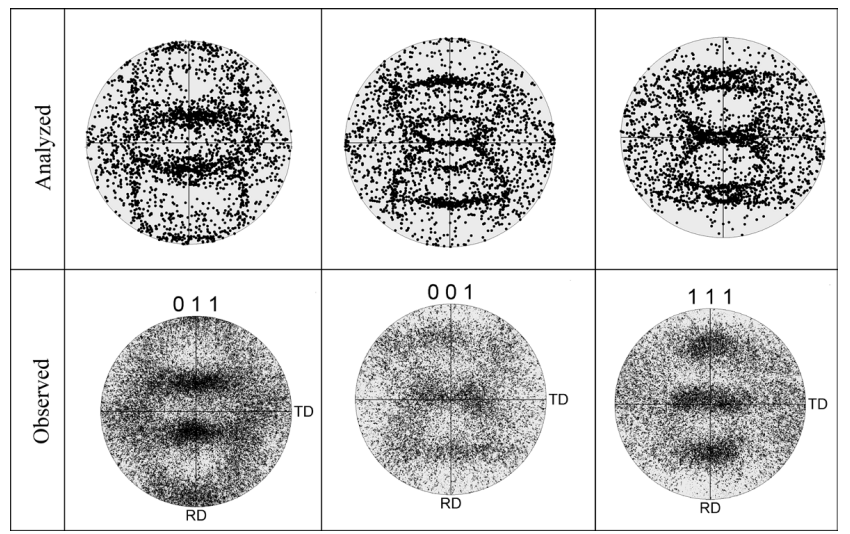

Fig. 10. Analyzed and observed transformation texture of plain carbon fine grain steel rolled with high reduction and low temperature schedule at center of thickness.

mation is an effective method for ultra fine-grained steels. ${ }^{28)}$ Therefore, to analyze hot rolling texture more precisely, we must develop a recrystallization texture evaluation method.

\section{Conclusions}

We formulated a macro-micro combined model to analyze microstructure and texture evolution, which enables us to predict the hot rolling texture in a nonrecrystallized austenite region and the austenite/ferrite transformation texture. Using this model, we can predict the hot rolling texture of SUS304 stainless steel and the transformation texture of fine-graind plain carbon steel with high-reduction low-temperature rolling in a tandem hot strip mill. The prediction accuracy of the texture is good. However, partial recrystallization might occur as for the SUS304 stainless

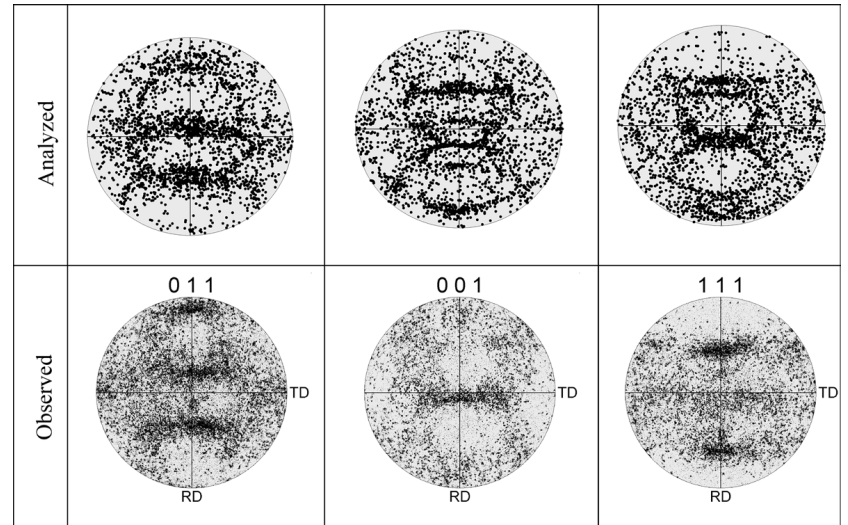

Fig. 11. Analyzed and observed transformation texture of plain carbon fine grain steel rolled with high reduction and low temperature schedule at surface.

steel strip and the fine-grained plain carbon strip rolled with high reduction at a low temperature. To predict the hot rolling texture more precisely, we must develop a recrystallization texture evaluation method.

\section{Acknowledgments}

This study was carried out with reference to the variant selection rules proposed by Dr. Hiroshi Fujiwara of Ritsumeikan University, to whom we are deeply grateful.

\section{REFERENCES}

1) T. Sakai, Y. Watanabe and H. Utsunomiya: Mater. Sci. Forum, 618-619 (2009), 483.

2) H. Inoue and T. Takasugi: Mater. Trans., 48 (2007), 2014.

3) J. Kubodera, I. Nakaoka and T. Nagamine: Tetsu-to-Hagané, 52 (1966), 1171.

4) H. Inagaki, K. Kurihara and I. Kozasu: Tetsu-to-Hagané, 61 (1975), 991.

5) H. Takechi, H. Katoh and T. Kakunan: J. Jpn. Inst. Met., 31 (1967), 717.

6) S. Matsuo: J. Jpn. Inst. Met., 19 (1980), 192.

7) K. Kimura and A. Takahashi: Nippon Steel Technical Rep., 389 (2009), 51.

8) G. I. Taylor: Royal Soc. Proc. A, 116 (1927), 16

9) R. J. Asaro and A. Needleman: Acta Metall., 33 (1985), 923

10) H. Motohashi, H. Takahashi and S. Tsuchida: J. Jpn. Soc. Technol. Plast., 37 (1996), 201

11) K. Sekine and T. Kamijo: J. Jpn. Inst. Met., 39 (1975), 1045.

12) T. Maeda, S. Hattori and K. Ishikawa: J. Jpn. Soc. Technol. Plast., 40 (1999), 591.

13) J. Yanagimoto and Y. Kakuta: CAMP-ISIJ, 14 (2001), 468.

14) T. Morimoto, R. Kurahashi, I. Chikushi and J. Yanagimoto: Tetsu-toHagané, 88 (2002), 747.

15) S. Nagashima: Shugososhiki, Maruzen, Tokyo, (1984), 197.

16) E. Furubayashi: Tetsu-to-Hagané, 71 (1985), 1155

17) H. Fujiwara, M. Yonezawa and K. Ameyama: J. Jpn. Inst. Met., 62 (1998), 803.

18) H. Fujiwara and K. Ameyama: J. Jpn. Inst. Met., 63 (1999), 187.

19) T. Tomida, M. Wakita, M. Yoshida, M. Imai and Y. Tanaka: Curr. Adv. Mater. Process., 22 (2009), 1191.

$20)$ E. H. Lee: J. Appl. Mech., 36 (1969), 1.

21) S. Nagata and J. Yanagimoto: Fundamentals in Metal Forming, Corona Publishing, Tokyo, (1997), 42.

22) J. Yanagimoto, K. Karhausen, A. J. Brand and R. Kopp: Trans. ASME, J. Manufact. Sci. Eng., 120 (1998), No. 2, 316.

23) J. Yanagimoto and J. Liu: ISIJ Int., 39 (1999), 171.

24) H. Fujiwara and K. Ameyama: Materia Jpn., 42 (2003), 487.

25) T. Morimoto, F. Yoshida, I. Chikushi, H. Kitahara and N. Tsuji: Tetsu-to-Hagané, 93 (2007), 591.

26) T. Morimoto, R. Kurahash, I. Chikushi and J. Yanagimoto: Tetsu-toHagané, 92 (2006), 601.

27) J. J. Jonas: Proc. of the 7th Int. Conf. on Steel Rolling, ISIJ, Tokyo, (1998), 524

28) H. Nakajima, T. Yamashita, T. Inoue, S. Torizuka, T. Hanamura and K. Nagai: Tetsu-to-Hagané, 89 (2003), 281. 